\title{
Adrenomedullin production is increased in normal human pregnancy
}

\author{
Romolo Di Iorio, Emanuela Marinoni, Claudio Letizia ${ }^{1}$, Barbara Villaccio, Alessandro Alberini and
} Ermelando V Cosmi Laboratory of Perinatal Medicine and Molecular Biology, 2nd Institute of Obstetrics and Gynecology and ${ }^{1}$ Department of Internal Medicine,
University 'La Sapienza', Rome, Italy

(Correspondence should be addressed to R Di Iorio, Laboratory of Perinatal Medicine and Molecular Biology, 2nd Institute of Obstetrics and Gynecology, University 'La Sapienza', Viale Regina Elena, 324, I-00161 Rome, Italy)

\begin{abstract}
Objective: Adrenomedullin, a recently discovered vasoactive peptide originally identified in pheochromocytoma, has been found to be increased in the plasma of pregnant women at term. This study was designed to elucidate whether adrenomedullin secretion is dependent on gestational age and the possible source and function of this peptide in human pregnancy.

Study design: Adrenomedullin concentrations were determined by RIA in amniotic fluid and maternal plasma obtained from 110 pregnant women between 8 and 40 weeks of gestation. Subjects were stratified into five groups according to gestational age. In term patients $(n=15)$, adrenomedullin was also measured in the umbilical artery and vein separately.

Results: High concentrations of adrenomedullin were present in plasma and amniotic fluid samples from patients in the first, second and third trimester. There was no significant difference in mean maternal plasma concentration of adrenomedullin between the five patient groupings. Amniotic fluid adrenomedullin concentrations decreased from $81.2 \pm 11.7 \mathrm{pg} / \mathrm{ml}$ at $8-12$ weeks of gestation to $63.7 \pm 6.0 \mathrm{pg} / \mathrm{ml}$ at $13-20$ weeks of gestation and then increased at 21-28 weeks of gestation to $99.1 \pm 10.4 \mathrm{pg} / \mathrm{ml}$. A further increase was found in samples collected after 37 weeks of gestation $(132.6 \pm 10.1 \mathrm{pg} / \mathrm{ml})$. In the umbilical vein, adrenomedullin concentration was higher $(P<0.05)$ than in the artery $(65.7 \pm 6.1 \mathrm{pg} / \mathrm{ml}$ and $48.5 \pm 5.2 \mathrm{pg} / \mathrm{ml}$ respectively), suggesting that adrenomedullin in the fetal circulation derives from the placenta.

Conclusions: Our results demonstrate the presence of adrenomedullin in maternal plasma and amniotic fluid throughout gestation, and show that its production starts very early in gestation, suggesting that this hormone may have an important role in human reproduction, from implantation to delivery.
\end{abstract}

European Journal of Endocrinology 140 201-206

\section{Introduction}

Adrenomedullin is a novel peptide first isolated from human pheochromocytoma (1). Northern blot analysis has shown that adrenomedullin mRNA is expressed not only in the adrenal gland, but also in various tissues including lung, heart, aorta, stomach, intestine, kidney, and thyroid gland (2). It has been reported that cultured vascular smooth muscle cells contain adrenomedullin mRNA and that endothelial cells produce adrenomedullin, which acts on specific receptors eliciting a long-lasting vasodilatation through the synthesis of cAMP (3). Immunocytochemistry studies have shown that adrenomedullin is widely distributed in the endocrine and neuroendocrine system, where it may play a role in the control of systemic and local circulation (4), and of humoral secretion. It has been demonstrated that adrenomedullin inhibits the secretion of adrenocorticotrophin (ACTH) (5), aldosterone (6), and insulin (7) and its secretion is stimulated by the thyroid hormones, progesterone and dexamethasone (8).

Recently, we have found high concentrations of adrenomedullin in maternal and umbilical cord plasma, in amniotic fluid in term human pregnancy (9) and in placental extracts (10), suggesting a potential role of this peptide during gestation. Furthermore, it has been shown that epithelial cells of fetal membranes express adrenomedullin mRNA and immunoreactive adrenomedullin has been detected in amniotic fluid in mid-gestation (11).

The purpose of this study was to examine concentrations of adrenomedullin in maternal plasma and amniotic fluid throughout pregnancy and to evaluate possible associations between maternal and amniotic fluid adrenomedullin concentrations as well as gestational age, to elucidate the physiological implication of adrenomedullin in human pregnancy. 


\section{Materials and methods}

\section{Patient population and study design}

One hundred and ten pregnant women from 8 to 40 weeks of gestation were enrolled into the study: 73 underwent transabdominal amniocentesis between 13 and 36 weeks of gestation, 22 had first trimester termination of pregnancy and 15 delivered by elective Caesarean section at term. As controls, 12 healthy nonpregnant women (age 23 to 36 years) were also studied. None of the pregnant women was in labour or experienced uterine contractions. Indications for amniocentesis included prenatal diagnosis (maternal age $>35$ years or family potential for genetic disease; $n=34$ ), abnormal triple-marker screen values (maternal serum $\alpha$-fetoprotein, human chorionic gonadotrophin and unconjugated oestriol; $n=9$ ), exclusion of fetal infection by cytomegalovirus (CMV) (PCR technique) suspected on the basis of maternal serology $(n=30)$. Women with multiple pregnancies, fetal anomalies, diabetes, pre-eclampsia and intrauterine growth retardation were excluded from the study. Four patients were removed from the study for abnormal karyotype $(n=2)$ and CMV-DNA detection in the amniotic fluid $(n=2)$. In all the other patients, prenatal diagnosis as well as neonatal outcome were negative for chromosomal abnormalities or suspected infection. Gestational age was assessed through determination of menstrual dates and first trimester ultrasound scan. According to gestational age, patients were stratified into five groups (8-12 weeks, 13-20 weeks, 21-28 weeks, 29-36 weeks, and >37 weeks; Table 1 ).

This study was approved by the local ethics committee and informed consent was obtained from all participants.

\section{Sample collection}

In patients undergoing transabdominal amniocentesis, the initial $3 \mathrm{ml}$ of amniotic fluid was collected and processed. In patients in the first trimester of pregnancy, amniotic fluid samples were obtained by needle aspiration under ultrasound guidance at the time of pregnancy termination. In pregnant women at term, samples were collected by transuterine amniocentesis at the time of elective Caesarean section. Briefly, amniotic fluid samples were immediately centrifuged after collection at $1800 \mathrm{~g}$ for $15 \mathrm{~min}$ at $4{ }^{\circ} \mathrm{C}$, the supernatants were divided into aliquots and stored at $-80^{\circ} \mathrm{C}$ until assayed.

Maternal blood samples were drawn from the cubital vein at the time of amniotic fluid sampling and just before the induction of anaesthesia in patients undergoing Caesarean section or pregnancy termination (Table 1). In patients at term (>37 weeks), paired fetal and maternal plasma samples were obtained. After delivery, the umbilical cord was clamped before any sign of breathing and blood was drawn from the artery and vein separately. Blood samples, anticoagulated with EDTA and aprotinin, were kept in ice until centrifuged and then stored at $-80^{\circ} \mathrm{C}$.

\section{Adrenomedullin determination}

Plasma and amniotic fluid adrenomedullin concentrations were measured after extraction and purification. Briefly, $2 \mathrm{ml}$ of sample was applied to conditioned SepPak C18 cartridges (Millipore Corp., Waters Chromatography, Mildford, MA, USA) and the column was sequentially washed with $5 \mathrm{ml}$ isotonic saline, $5 \mathrm{ml}$ $0.1 \%$ trifluoracetic acid and $5 \mathrm{ml} 20 \%$ acetonitrile in $0.1 \%$ trifluoracetic acid. The absorbed material was eluted with $4 \mathrm{ml} 50 \%$ acetonitrile and the elute was lyophilized. After lyophilization, samples were dissolved in $50 \mathrm{mmol} / \mathrm{l}$ phosphate buffer $(\mathrm{pH} \mathrm{7.4)}$ and adrenomedullin was measured in plasma and amniotic fluid by RIA using a commercial kit (Phoenix Pharmaceuticals Inc., Mountain View, CA, USA) with rabbit polyclonal antibody raised against human adrenomedullin 1-52. The sensitivity of the assay was $2 \mathrm{pg} / \mathrm{tube}$. The antibody cross-reacts $100 \%$ with human adrenomedullin and no cross-reactivity was reported with rat adrenomedullin,

Table 1 Characteristics of women with uncomplicated pregnancies for five gestational age groupings and non-pregnant controls.

\begin{tabular}{|c|c|c|c|c|c|c|}
\hline & \multicolumn{5}{|c|}{ Pregnant women } & \multirow{2}{*}{$\begin{array}{c}\text { Non-pregnant } \\
\text { women }\end{array}$} \\
\hline & $8-12$ weeks & 13-20 weeks & 21-28 weeks & 29-36 weeks & $>37$ weeks & \\
\hline Age (years) & $26.2 \pm 5.8$ & $35.4 \pm 3.2$ & $28.6 \pm 3.6$ & $27.4 \pm 4.1$ & $26.8 \pm 4.2$ & $27.1 \pm 5.3$ \\
\hline Parity & $1.1 \pm 0.4$ & $1.5 \pm 0.6$ & $0.8 \pm 0.5$ & $1.0 \pm 0.4$ & $1.4 \pm 0.8$ & $1.2 \pm 0.5$ \\
\hline Gestational age at sampling (weeks) & $10.3 \pm 1.0$ & $16.4 \pm 1.3$ & $24.7 \pm 3.0$ & $33.0 \pm 2.2$ & $38.7 \pm 1.1$ & - \\
\hline Weight $(\mathrm{kg})$ & $59 \pm 8$ & $62 \pm 9$ & $65 \pm 9$ & $67 \pm 10$ & $71 \pm 12$ & $56 \pm 7$ \\
\hline Systolic blood pressure (mmHg) & $111 \pm 14$ & $106 \pm 15$ & $110 \pm 13$ & $113 \pm 15$ & $118 \pm 16$ & $112 \pm 12$ \\
\hline Diastolic blood pressure (mmHg) & $67 \pm 11$ & $63 \pm 9$ & $66 \pm 10$ & $66 \pm 13$ & $68 \pm 14$ & $69 \pm 11$ \\
\hline Maternal blood samples $(n)$ & 20 & 25 & 15 & 18 & 15 & 12 \\
\hline Cord blood samples & - & - & - & - & 15 & - \\
\hline Amniotic fluid samples $(n)$ & 22 & 36 & 15 & 18 & 15 & - \\
\hline
\end{tabular}

Results are mean values \pm S.D. 
amylin, calcitonin-gene-related peptide, endothelin-1 (ET-1), $\alpha$-atrial natriuretic peptide or brain natriuretic peptide. The intra- and interassay coefficients of variance were $5.1 \%$ and $12.0 \%$ respectively.

\section{Statistics}

Adrenomedullin concentrations are expressed as mean values \pm s.E.M. Statistical analysis was performed with determination of Spearman rank order correlation and comparison between groups by Kruskal-Wallis oneway ANOVA and the Mann-Whitney U test when data were not normally distributed. The clinical characteristics of the women are expressed as mean \pm s.D. and were compared by Student's $t$-test for unpaired data. To compare proportions between groups, Fisher's exact test was used. Statistical significance was set at $P<0.05$.

\section{Results}

Adrenomedullin was detected in all maternal plasma and amniotic fluid samples from patients in the first, second and third trimester and in umbilical plasma at term. There was no significant difference in mean maternal plasma concentrations of adrenomedullin between the five patient groupings (Fig. 1); at all stages adrenomedullin concentrations were higher than in non-pregnant subjects, being $10.7 \pm 1.3 \mathrm{pg} / \mathrm{ml}$. Adrenomedullin levels were significantly higher $(P<0.05)$ in the umbilical vein $(65.7 \pm 6.1 \mathrm{pg} / \mathrm{ml})$ than in the artery $(48.5 \pm 5.2 \mathrm{pg} / \mathrm{ml})$ (Fig. 2). No significant correlation was found between maternal and either umbilical vein (correlation coefficient: 0.020) or umbilical artery (correlation coefficient: 0.103) adrenomedullin concentrations.
We found a positive correlation between amniotic fluid adrenomedullin concentrations and gestational age (correlation coefficient: $0.346, P<0.001$ ), although amniotic fluid adrenomedullin levels decreased from $81.2 \pm 11.7 \mathrm{pg} / \mathrm{ml}$ at $8-12$ weeks of gestation to $63.7 \pm 6.0 \mathrm{pg} / \mathrm{ml}$ at $13-20$ weeks of gestation, and then increased at 21-28 weeks of gestation to $99.1 \pm 10.4 \mathrm{pg} / \mathrm{ml}(P<0.05)$. A further increase was found in samples collected after 37 weeks of gestation (132.6 $\pm 10.1 \mathrm{pg} / \mathrm{ml} ; P<0.01$ vs $8-12$ and $13-20$ week groups and $P<0.05$ vs $21-28$ and 29-36 week groups; Fig. 1). No correlation was found between maternal plasma adrenomedullin concentration and amniotic fluid levels (correlation coefficient: 0.101).

\section{Discussion}

This study confirms our previous finding of elevated concentrations of adrenomedullin in human pregnancy (9). Plasma adrenomedullin levels in pregnant women are from three- to fivefold higher than in nonpregnant women and this increase was found in samples collected as early as 8 weeks and was maintained throughout gestation, suggesting an enhanced synthesis of this peptide in pregnancy. We found a slight increase in maternal plasma concentration as gestational age progressed, although it was not significant. A lack of a significant increase in maternal plasma adrenomedullin levels may be due to the physiological adaptation of the maternal vascular system to pregnancy, in particular to an increase in maternal blood volume that determines hemodilution of plasma proteins during the second and third trimesters of pregnancy. Different tissues may be responsible for
Figure 1 Maternal plasma (open bars) and amniotic fluid (hatched bars) adrenomedullin mean concentrations throughout pregnancy. Subjects are in five groups from 8 to 40 weeks. No differences were observed in maternal plasma levels among the groups. Differences in amniotic fluid adrenomedullin concentrations were found: $\mathrm{a}, P<0.05$ vs $13-20$ weeks; $b, P<0.01$ vs $8-12$ and $13-20$ weeks; , $P<0.05$ vs $21-28$ and $29-36$ weeks.

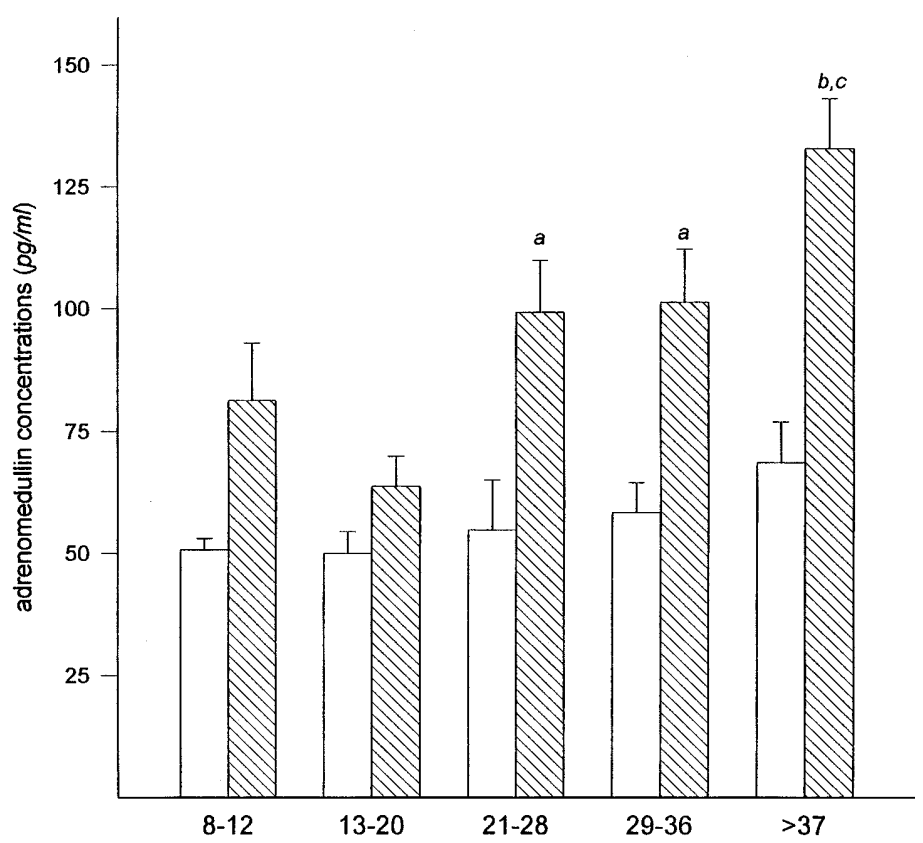




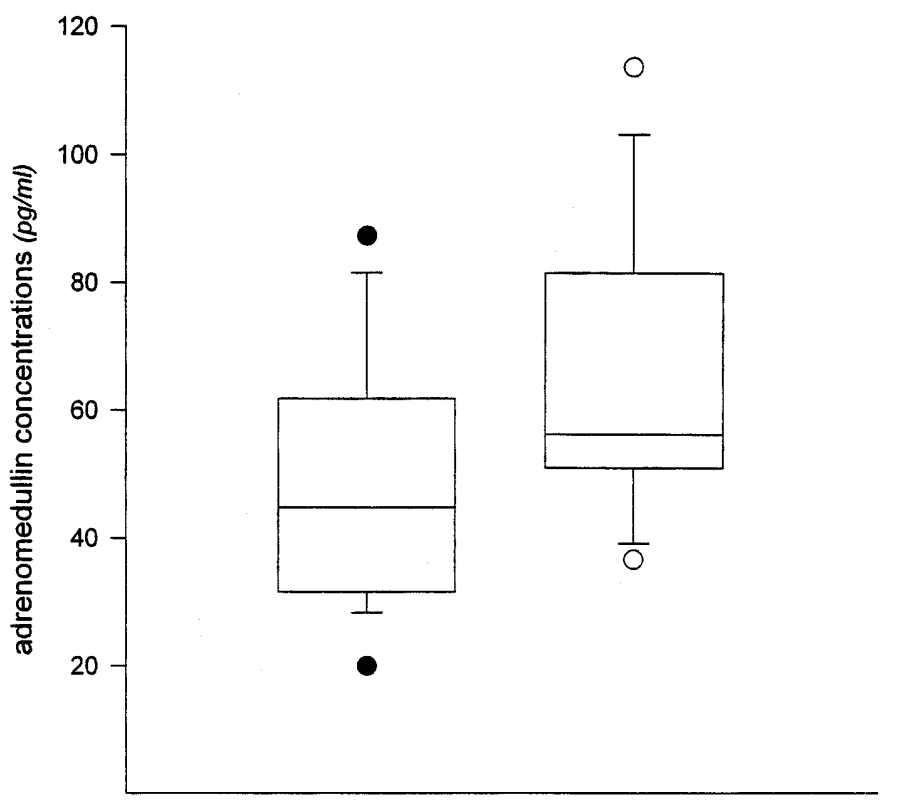

Figure 2 Concentrations of adrenomedullin in umbilical artery $(\bullet)$ and vein $(O)$ at term. The lower and upper bars represent the 10th and 90th centiles respectively, and the interquartile range is indicated by the box, the median value being the horizontal line in the box. Adrenomedullin values were significantly higher $(P<0.05)$ in the umbilical vein. increased adrenomedullin production in pregnancy, including maternal endothelial cells, heart, lung and several other tissues.

In cord plasma, adrenomedullin levels were significantly higher in the umbilical vein than in the artery, indicating that adrenomedullin in the fetal circulation is of placental origin. We did not find any significant correlation between fetal and maternal adrenomedullin concentrations. This finding may indicate that adrenomedullin in umbilical plasma is not derived from maternal circulation, but rather from the placenta. There is strong evidence that feto-placental tissues represent an additional site of adrenomedullin production. We have reported previously (10) that in term human pregnancy immunoreactive adrenomedullin is localized in the trophoblast cells of the placenta and fetal membranes and in the epithelial cells of the amnion; high concentrations of this peptide are detectable in the placenta and fetal membrane extracts. Furthermore, Macri et al. (11) have indicated the expression of mRNA for adrenomedullin in the amniotic cells of fetal membranes. Together these findings indicate that the feto-placental unit secretes large amounts of adrenomedullin and that this could be the main source of adrenomedullin in amniotic fluid. Adrenomedullin circulating in maternal plasma may derive either from maternal or feto-placental tissues, although lack of correlation between plasma and amniotic fluid adrenomedullin concentrations seems to argue against this origin. It is likely that both the placenta and the mother secrete adrenomedullin during pregnancy and that it may act as a circulating hormone on maternal homeostasis and as a local paracrine/ autocrine factor, regulating local vascular tone and humoral secretion in feto-placental tissues.
Amniotic fluid adrenomedullin concentration should better reflect adrenomedullin production from fetoplacental tissues. In the present study we found that, as in maternal plasma, adrenomedullin was detectable in amniotic fluid collected in very early pregnancy, but in contrast with maternal plasma, amniotic fluid adrenomedullin levels increased with gestational age. In normal pregnancy, adrenomedullin concentration in amniotic fluid was higher than in maternal blood at any gestational age and increased significantly after 20 weeks of gestation. In term patients, amniotic fluid adrenomedullin concentrations further increased, indicating that fetal and/or placental adrenomedullin production is enhanced as pregnancy progresses.

The physiological meaning of the increased production of adrenomedullin in pregnancy is unknown, although we can speculate that it may contribute to the adaptation of the maternal vascular system to pregnancy. It is well known that during normal pregnancy physiological adaptations occur in the mother which ensure an adequate blood supply to the fetus. Vascular resistance, mean arterial pressure, and sensitivity to endogenous constrictors are reduced, and cardiac output, heart rate and blood volume are increased (12). Adrenomedullin elicits a long-lasting vasorelaxant action and has been suggested to participate in the control of blood pressure and vascular homeostasis; thus circulating adrenomedullin may be implicated in the maintenance of low vascular resistance during pregnancy.

Adrenomedullin secreted by feto-placental tissues may have a different role, acting locally. Recent data suggest the involvement of this hormone in the regulation of growth. Adrenomedullin stimulates DNA synthesis and cell proliferation of Swiss 3T3 fibroblasts 
acting via the elevation of intracellular cAMP (13), and inhibits fetal calf serum-stimulated proliferation in cultured rat vascular smooth muscle cells in a paracrine fashion (14). Moreover, it has been reported that adrenomedullin acts as a growth factor in several normal and malignant tissues (15) and it is well known that trophoblast cells share in vitro and in vivo invasive properties with malignant cells. mRNA for both adrenomedullin and adrenomedullin receptors has been found in embryonic and extraembryonic developing mouse and rat tissues, and in fetal and maternal tissues of corresponding primitive placenta; adrenomedullin increases during late organogenetic and early fetal growth periods (16). The distribution pattern of this peptide during development is similar to other growth factors (insulin-like growth factor, transforming growth factor- $\beta$ and platelet-derived growth factor) indicating that adrenomedullin could be involved in analogous functions. These data are of particular interest in view of the elevated concentrations of adrenomedullin detected in early pregnancy. We found a significant increase in amniotic fluid adrenomedullin in the second half of the second trimester of pregnancy compared with the first half of pregnancy that correlates with late organogenesis and early fetal growth in humans. Furthermore, we have reported previously that immunoreactive adrenomedullin is localized in extravillous trophoblast and decidua cells of human placenta (10). Cytotrophoblast invasion is a dynamic change in cell-cell and cell-matrix interaction which can be assimilated to an inflammatory reaction. Since adrenomedullin secretion is stimulated by cytokines, such as tumor necrosis factor- $\alpha$ and interleukin$1 \alpha$ (17) it is therefore possible that this hormone may play a role in the regulation of trophoblast invasion of maternal decidua during human implantation, or in processes correlated with embryonic development, such as the control of growth and differentiation.

Increased adrenomedullin concentrations in amniotic fluid in late gestation may suggest that this hormone is implicated in the regulation of utero-placental and fetal circulation (18). Recent studies have shown that adrenomedullin might modulate vascular tone as a paracrine regulator, through the inhibition and/or stimulation of vasoactive agents such as nitric oxide (19) and ET-1 (20), produced by feto-placental tissues, which have been demonstrated to regulate placental circulation $(21,22)$. Furthermore both these agents are involved in the control of myometrial contractility (23, 24 ), and a preliminary study has shown that adrenomedullin exerts an inhibitory effect upon the contractile response of rat uterine muscle to galanin (25), suggesting that adrenomedullin, directly through the cAMP or indirectly through the regulation of other modulators, could also affect uterine contractility.

In conclusion, this study provides evidence that adrenomedullin is secreted in high concentrations throughout gestation, and that its production starts very early in pregnancy, suggesting that it may have an important role in human reproduction, from implantation to delivery.

\section{Acknowledgements}

This work was supported by the Italian National Research Council (CNR) (grant No. 96.01764.CT11).

\section{References}

1 Kitamura K, Kangawa K, Kawamoto M, Ichiki Y, Nakamura S, Matsuo H \& Eto T. Adrenomedullin: a novel hypotensive peptide isolated from human pheochromocytoma. Biochemical and Biophysical Research Communications 1993192 553-560.

2 Ichiki Y, Kitamura K, Kangawa K, Kawamoto M, Matsuo H \& Eto T. Distribution and characterization of immunoreactive adrenomedullin in human tissue and plasma. FEBS Letters 1994338 6-10.

3 Ishizaka Y, Tanaka M, Kitamura K, Kangawa K, Minamino N, Matsuo $\mathrm{H} \&$ Eto $\mathrm{T}$. Adrenomedullin stimulates cyclic AMP formation in rat vascular smooth muscle cells. Biochemical and Biophysical Research Communications 1994200 642-646.

4 Ishiyama Y, Kitamura K, Ichiki Y, Nakamura S, Kida O, Kangawa $\mathrm{K} \&$ Eto T. Hemodynamic effects of a novel hypotensive peptide, human adrenomedullin. European Journal of Pharmacology 1993 $241271-273$.

5 Samson WK, Murphy T \& Schell DA. A novel vasoactive peptide, adrenomedullin, inhibits pituitary adrenocorticotropin release. Endocrinology 1995136 2349-2352.

6 Yamaguchi T, Baba K, Doi Y \& Yano K. Effect of adrenomedullin on aldosterone secretion by dispersed rat adrenal zona glomerulosa cells. Life Sciences 199556 379-387.

7 Martínez A, Weaver C, López J. Bhathena SJ. Elgasser TH, Miller MJ et al. Regulation of insulin secretion and blood glucose metabolism by adrenomedullim. Endocrinology 1996137 26-32.

8 Minamino N, Shoji H, Sugo S, Kangawa K \& Matsuo H. Adrenocortical steroids, thyroid hormones and retinoic acid augment the production of adrenomedullin in vascular smooth muscle cells. Biochemical and Biophysical Research Communications $1995211686-693$.

9 Di Iorio R, Marinoni E, Scavo D, Letizia C \& Cosmi EV. Adrenomedullin in pregnancy. Lancet 1997349328.

10 Marinoni E, Di Iorio R, Letizia C, Villaccio B, Scucchi L \& Cosmi EV. Immunoreactive adrenomedullin in human fetoplacental tissues. American Journal of Obstetrics and Gynecology 1998179 784-787.

11 Macri CJ, Martinez A, Moody TW, Gray KD, Miller MJ, Gallagher M et al. Detection of adrenomedullin, a hypotensive peptide, in amniotic fluid and fetal membranes. American Journal of Obstetrics and Gynecology 1996175 906-911.

12 Robson SC, Hunter S, Boys RJ \& Dunlop W. Serial study of factors influencing changes in cardiac output during human pregnancy. American Journal of Physiology 1989256 H1060-H1065.

13 Withers DJ, Coppock HA, Seufferlein T, Smith DM, Bloom SR \& Rozengurt E. Adrenomedullin stimulates DNA synthesis and cell proliferation via elevation of cAMP in Swiss $3 \mathrm{~T} 3$ cells. FEBS Letters 1996378 83-87.

14 Kano H, Kohno M, Yasunari K, Yokokawa K, Horio H, Ikeda M, et al. Adrenomedullin as a novel antiproliferative factor of vascular smooth muscle cells. Journal of Hypertension 199614 209-213.

15 Miller MJ, Martinez A, Unsworth EJ, Thiele CJ, Moody JW \& Cuttitta F. Adrenomedullin expression in human tumor cell lines and its potential role as an autocrine growth factor. Journal of Biological Chemistry 1996271 23345-23351.

16 Montuenga LM, Martínez A, Miller MJ, Unsworth EJ \& Cuttitta F. Expression of adrenomedullin and its receptor during embryogenesis suggests autocrine or paracrine modes of action. Endocrinology $1997138440-451$. 
17 Sugo S, Minamino N, Shoji H, Kangawa K, Kitamura K, Eto T et al. Interleukin-1, tumor necrosis factor and lipopolysaccharide additively stimulate production of adrenomedullin in vascular smooth muscle cells. Biochemical and Biophysical Research Communications 1995207 25-32.

18 Di Iorio R, Marinoni E, Letizia C, Alò P, Villaccio B \& Cosmi EV. Adrenomedullin, a new vasoactive peptide, is increased in preeclampsia. Hypertension 199832 758-763.

19 Miura K, Ebara T, Okumura M, Matsuura T, Kim S, Yukimura T et al. Attenuation of adrenomedullin-induced renal vasodilatation by $\mathrm{N}^{\mathrm{G}}$-nitro L-arginine but not glibenclamide. British Journal of Pharmacology 1995115 917-924.

20 Kohno M, Kano H, Horio T, Yokokawa K, Yasunari K \& Takeda T. Inhibition of endothelin production by adrenomedullin in vascular smooth muscle cells. Hypertension 199525 1185-1190.

21 Wilkes BM, Mento PF, Hollander AM, Maita ME, Sung S \& Girard EP. Endothelin receptors in human placenta: relationship to vascular resistance and thromboxane release. American Journal of Physiology 1990258 E864-E870.

22 Di Iorio R, Marinoni E, Coacci F, la Torre R \& Cosmi EV. Amniotic fluid nitric oxide and uteroplacental blood flow in pregnancy complicated by intrauterine growth retardation. British Journal of Obstetrics and Gynaecology 1997104 1134-1139.

23 Izumi H, Yallampalli C \& Garfield RE. Gestational changes in L-arginine-induced relaxation of pregnant rat and human myometrial smooth muscle. American Journal of Obstetrics and Gynecology $19931691327-1337$.

24 Word RA, Kamm KE \& Casey ML. Contractile effect of prostaglandins, oxytocin and endothelin-1 in human myometrium in vitro: refractoriness of myometrial tissue of pregnant women to prostaglandin $\mathrm{E}_{2}$ and $\mathrm{F}_{2 \alpha}$. Journal of Clinical Endocrinology and Metabolism 199275 1027-1032.

25 Upton PD, Austin C, Taylor GM, Nandha KA, Clark AJL, Ghatei MA et al. Expression of adrenomedullin (ADM) and its binding sites in the rat uterus: increased number of binding sites and ADM messenger ribonucleic acid in 20-day pregnant rats compared with nonpregnant rats. Endocrinology 1997138 2508-2514.

Received 7 August 1998

Accepted 27 November 1998 